Quality InNovation Prosperity / KVAlita InOVÁCia ProsPerita XVI/2 - 2012103

\title{
IDEA OF QUALITY VERSUS IDEA OF EXCELLENCE
}

\author{
MARKO KIAUTA
}

\section{BACKGROUND}

We, professionals on the field of quality, are responsible to give to our customer honest clarification of fundamental ideas. Our marketing messages are often too much under influence of a single tool. Excellence model (EM), as a tool, is not alternative for ISO 9001. It is appropriate as un upgrade, applicable for those, which already reached sufficient level of quality management. Much too often, EM is offered as a solution for those, which did not succeed to usefully use ISO 9001 system or worse, for full beginners. Quality movement is losing credibility with such irresponsible selling of EM as new fashion, which suggests replacing the idea of quality with the idea of excellence.

Findings are based on more than 25 years of practice in professional promotion of quality: in consulting on private and public sector, from 1990 lead auditor at SIQ (Slovenian Institute of Quality), from 1998 lead assessor - commission for Slovenian Excellence Quality Award. Theory is developed based on: Noriaki Kano theory of Attractive quality, Tito Conti ideas on TQM (Total Quality Management) and applications problems of Excellence model, Practical case of General Hospital Novo Mesto (in 1998 first attempt of using EM, than forced to build QMS (Quality Management System) based on ISO 9001 and then returned to practice $\mathrm{EM})$.

\section{THE HYPOTHESES}

Excellence is the highest level of quality and is as such the goal of quality development efforts. EFQM Excellence Model is a model for quality management and as such would be more appropriate, if the name would be Quality Management Model of EFQM (QMM of EFQM). With such a name, it would be demonstrated, that this is not a new fad replacing the idea of quality, but a tool to upgrade efforts for quality development of an organization. The name Excellence Award for recognized excellent organizations is not misleading, but the name Excellence Model is. The name of EFQM Excellence Model should be replaced with QMM. 


\section{TEST OF HYPOTHESES}

\subsection{EFQM Excellence Model as a tool for development of organizations}

EFQM Excellence Model is a very useful tool for developing quality in the direction of excellence. And in practice it is not applied only for assessment and recognition of excellent examples. It is applied mainly as an improvement tool for all organizations, regardless on the reached level of quality. By definition, the excellent level is a privilege of positive minority. If we want to honestly suggested this tool to all organizations, we must admit, that huge majority will never rich the excellent level. I am convinced, that mission of EFQM is not focused on supporting efforts only to excellent minority, but it is for all organizations on their way of development quality. We, professionals on the field of quality, are responsible to give to our customer honest clarification of fundamental ideas. Our marketing messages are often confusing our clients by forcing the use of a single tool. Quality movement is losing credibility with such irresponsible selling of EFQM Excellence Model as new fashion, which suggests between the lines that the idea of excellence can replace the idea of quality.

\subsection{What can we learn from sports?}

If we compare contest for Excellence Award and contest for Olympic Games, all are focused on different disciplines (in the case of organizations collected in the Model), but in the case of sports in names of disciplines is no word of excellence. Sports practices are not devoted only to best participants, but to all participants. Pire De Coubertin, founder of the International Olympic Committee, underlined: It is important to participate, not to win (The important thing in life is not the triumph but the struggle, the essential thing is not to have conquered but to have fought well).

\subsection{Problems in the practice, caused by the name}

Many organizations (mainly in public sector), whose management is unprepared to be responsible and actively involved in systematical quality management, use assessment with EFQM Excellence Model or CAF (Common Assessment Framework) as an alternative for quality management and as an alibi, that they are responsibly active on the field of QM. We have situations that full beginners start to talk about excellence as an alternative for quality. They are as drivers beginners, trying to run Formula One. Those situations are mainly quilt of those, selling them quick fix. But the name Excellence Model is for them a big help. Those, who are allergic on classical long term heavy way of developing quality management, take this as a "methadone". But we all know that there is no shortcut. One of the biggest obstacles to successful implementation is overcoming the tendency of many companies to latch on to the next management fad or to implement quality standards and improvements methodologies as a "program".

On the other hand a lot of ISO practical applied QMS are too much bureaucratic and with too little value added. There is a symbiosis between management 
unwilling to involve and quality staff, which accept his "unique" role. Instead of developing QM documentation in the direction of knowledge management, many of "practical" quality experts are now "clearing" QM documentation to the level that is really less disturbing, but is also les helpful.

\subsection{Is idea of excellence fashion fad, replacing the idea of quality?}

The word "quality" typically has a narrower connotation associated with the quality of products and services the company delivers to its customers. But, businesses that have made quality an integral part of the way the business is designed, have successfully implemented a business strategy towards excellence. In these cases the meaning of the word "quality" goes beyond the quality of the products and services, and takes a broader meaning of maximizing the effectiveness of the business in meeting or exceeding customer value expectations. According Cobb (2003) the use of EFQM Model is not another fad.

We can learn from the Ichak Kalderon Adizes's thoughts about leadership (Adizes, 2011): "I would like to give a word of warning. In my judgment, this is another fad. We have seen the world »management « change over the years. At the beginning, the process was called »administration «. But when administration did not produce the desired results, the word administration was relegated to some middle management, to the bureaucrats. They still are administrators and a new word was created »management «. It was found, that administration is only a piece of the action and what we really need to amplify and to understand the concept in a much wider way. That didn't work either. The management process did not produce the results that were expected, so a new fad emerged. And it's the word executive - Chief Executive Officer (CEO). And the word management was relegated to »middle management «. Executives are much higher level. Now the word »executive« is not doing very well either. So now the new word has emerged: »Leadership«. It is the same lady in a different dress. We have not changed the paradigm of our thinking. We believe that by changing the name, when amplifying the concept, we are actually changing the phenomenon. But we are not. Or it's an administrator, a manager, an executive or a leader - the paradigm is still staying the same. And that's why it will not work. What we need is complementary team."

If we make a parallel between management and quality management, we can realized, that on the field of quality management "the same lady was in different dresses", from quality control, quality assurance, quality management, total quality management and finally management for Excellence. Many businesses have succumbed to the program du jour management trap, jumping from one management philosophy to the next looking for the ultimate solution.

When a need forced us to amplify the concept of quality, new elements must not be replacement for already existing ones, but a complementary addition.

Theory finds these complementary activities in different styles of managements which are represented with PAEI types (Producers, Administrators, 
Enterpreneurs, Integrators) (Adizes, 2011). And what types of quality management can we recognize?

\subsection{Three types of quality management styles}

\subsubsection{Three different qualities}

From Attractive Quality theory (Kano, 1984 cited in Wikipedia contributors, 2012) we learned about objective and subjective perception on Quality what lead us to three different qualities:

- Must be quality (fulfillment of demands),

- Competitive quality (fulfillment of expectations) and

- Attractive quality (fulfillment of new needs).

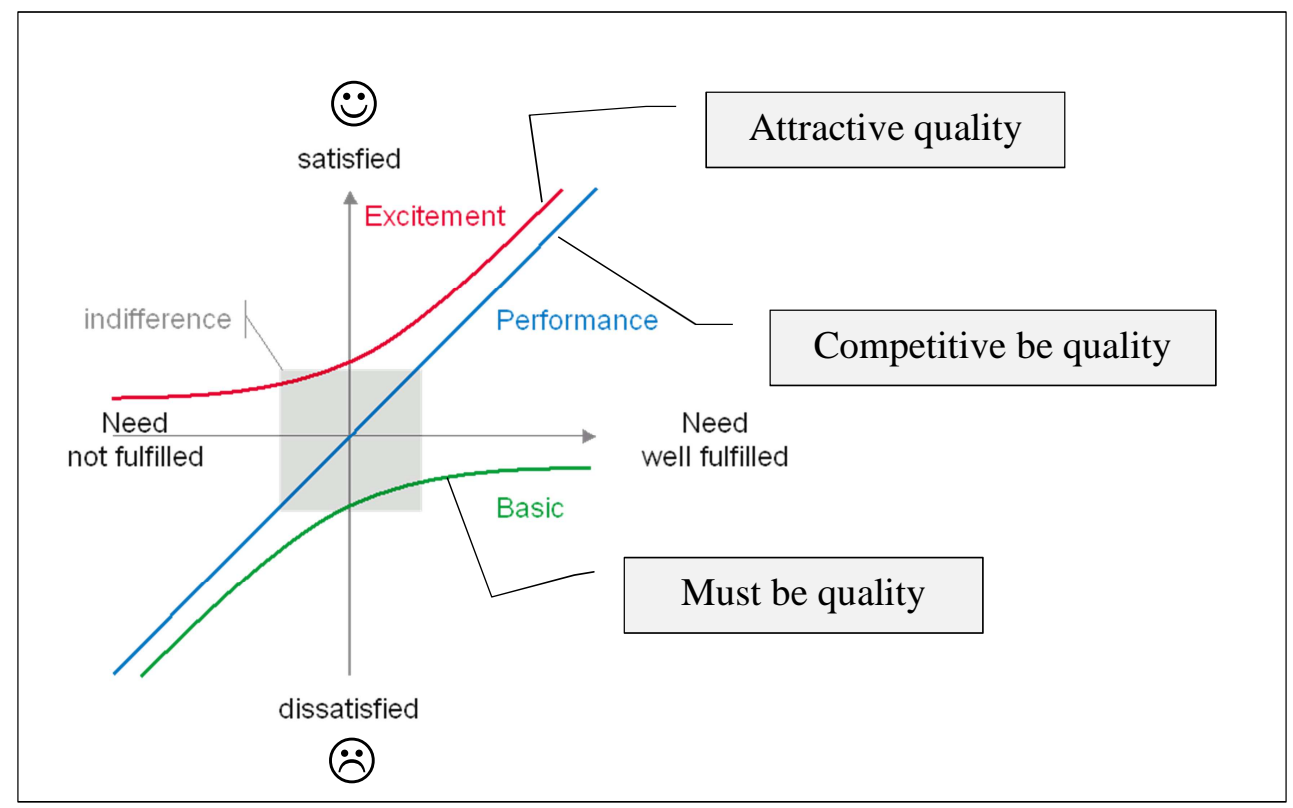

Diagram 1 -Attractive Quality (Wikipedia contributors, 2012)

\subsubsection{Three different focuses of quality management}

I related these three different qualities to three different parts of gauss distribution:

- Must quality is a challenge for negative minority and is about safety in broader meaning.

- Competitive quality is challenge for majority and is about delivering les or more value for customer.

- Attractive quality is challenge for positive minority and is about creating sustainability by reacting on new needs and new conditions. 


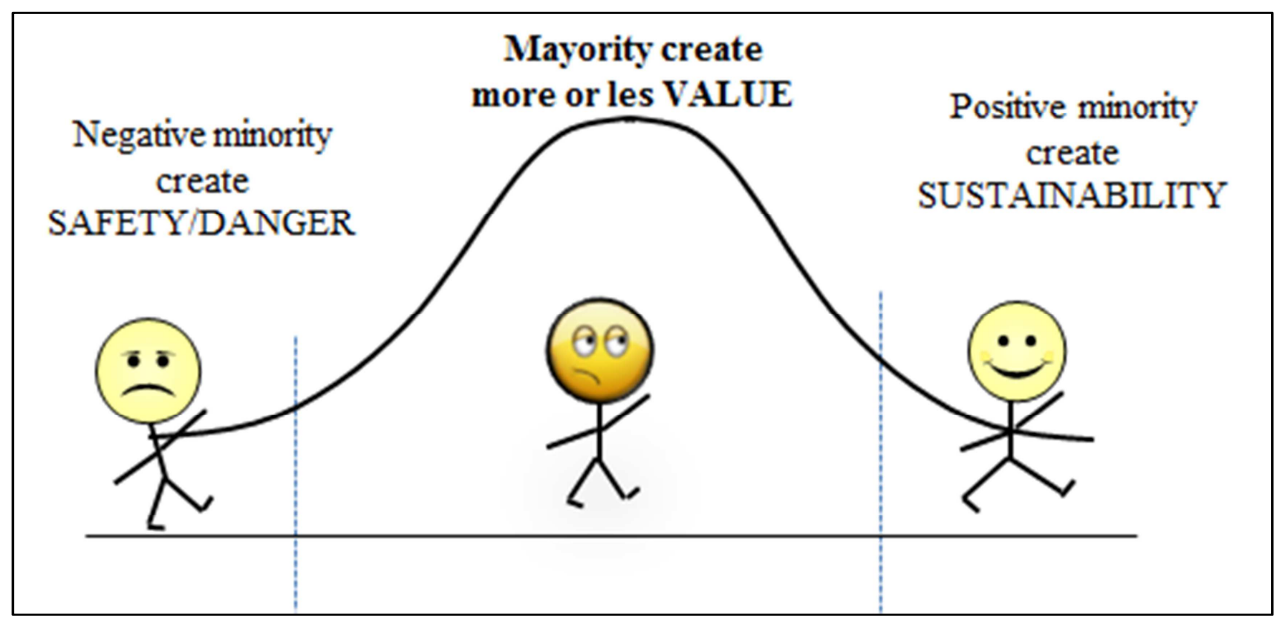

Diagram 2 - Three different qualities related to gauss distribution

(Kiauta, 2011)

Implementation of idea of quality in first phase was focused on negative aspects of finding and fixing bad quality. Quality specialists caused aversion of common people. They are against negative approach of looking for negative results everywhere and every time. The self-esteem was damaged, because there was not balance between good and bad elements. The reaction in the sector of public services is that organizations see in QMS something that is not constructive and useful. They were looking for something opposite. And they got it: Excellence Model and practice, looking for facts that evidence elements of excellence.

What is now wrong? The incomplete QM approach focused mainly on negative aspects / bad results was changed with another incomplete QM approach focused mainly on positive aspects / pieces of excellence. What could be better? We need integrity of QM approach, focused on all three fields of quality: bad, good and excellent quality. Healthy organizations and societies are those, where integration forces are stronger than those of disintegration. If not, systems are falling apart. If we allow incomplete QM approach (negative or positive focused), this is not good base for integration forces. Let us test this thesis. If we look only for bad quality, average reactions are efforts for no transparency what is very bad for integration efforts. If we look only for excellent quality, average reactions are efforts, to demonstrate superiority to the others, what also is bad for integration efforts. What we get from integrity of approach? If we promote importance of quality instead of excellence, we speak for all and all are addressed.

The idea of quality is for all; the idea of excellence is only for minority. 
Let us see, the relevance of both terms in Google:

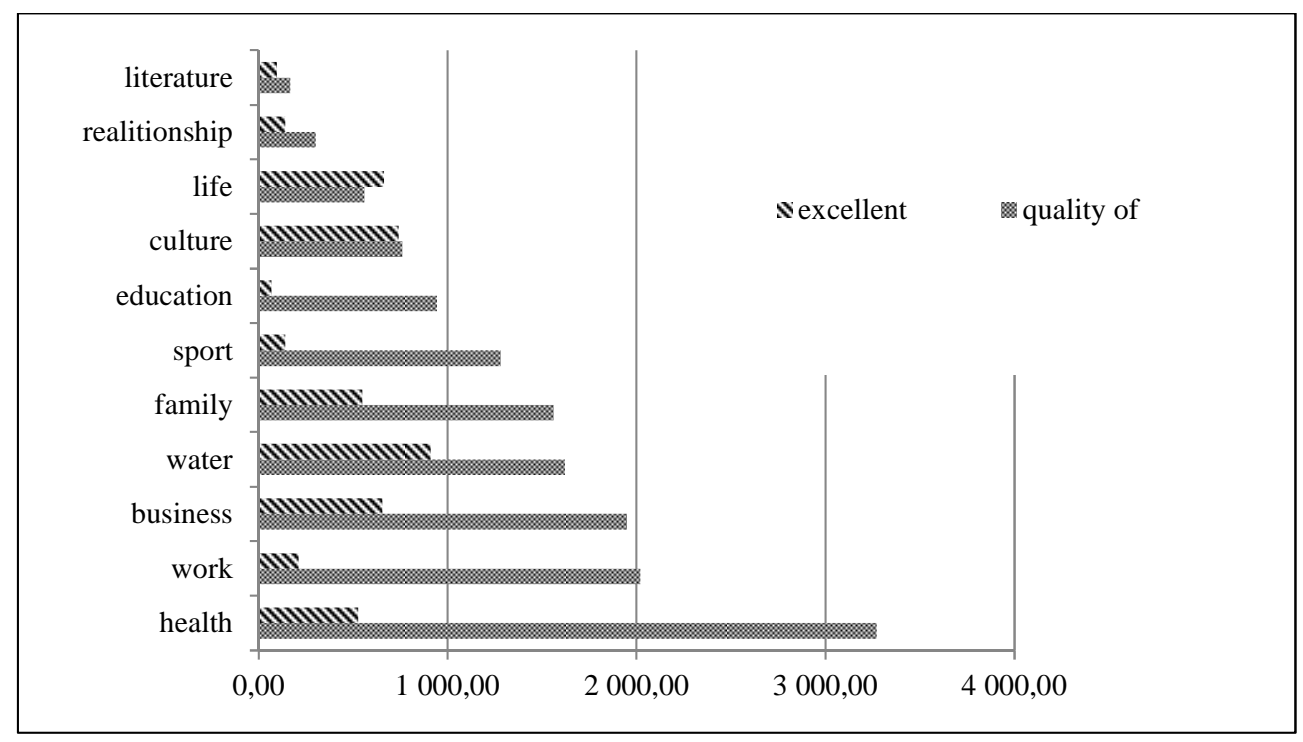

Diagram 3 - Millions of matches on Google on May 2011

We can assume that discussion about health is most serious and from that I understand excellent health as only one of possible states of quality of health.

\subsubsection{Three different reactions on changes}

In time of explosion of changes, agility is a matter of survive. »We either learn to fail or we fail to learn « (Shahar, 2012). The most significant differences in quality management approach are in regards of reaction on changes. If we follow the theory of How to Manage in Times of Crisis (Adizes, 2009), there are three reaction types on the change (see Diagram 4):

- Pro-active reaction in the period of time, when the change is only opportunity and not yet problem. We can assume that this is reaction of positive minority. There are three important advantages against re-active reaction:

○ much longer time (from change to problem),

$\circ$ no need to fix the problem, caused by non-adaption to change, and

$\circ$ positive atmosphere

- Re-active reaction, reacting only when opportunity develop into problem.

- No-active reaction, when people don't have possibilities to react or they only think, that this is not their duty.

We can see this situation in the "light" of Seneca's wisdom (see diagram 5):

"Destiny is leading those who are willing, and swallow those, who are not." 


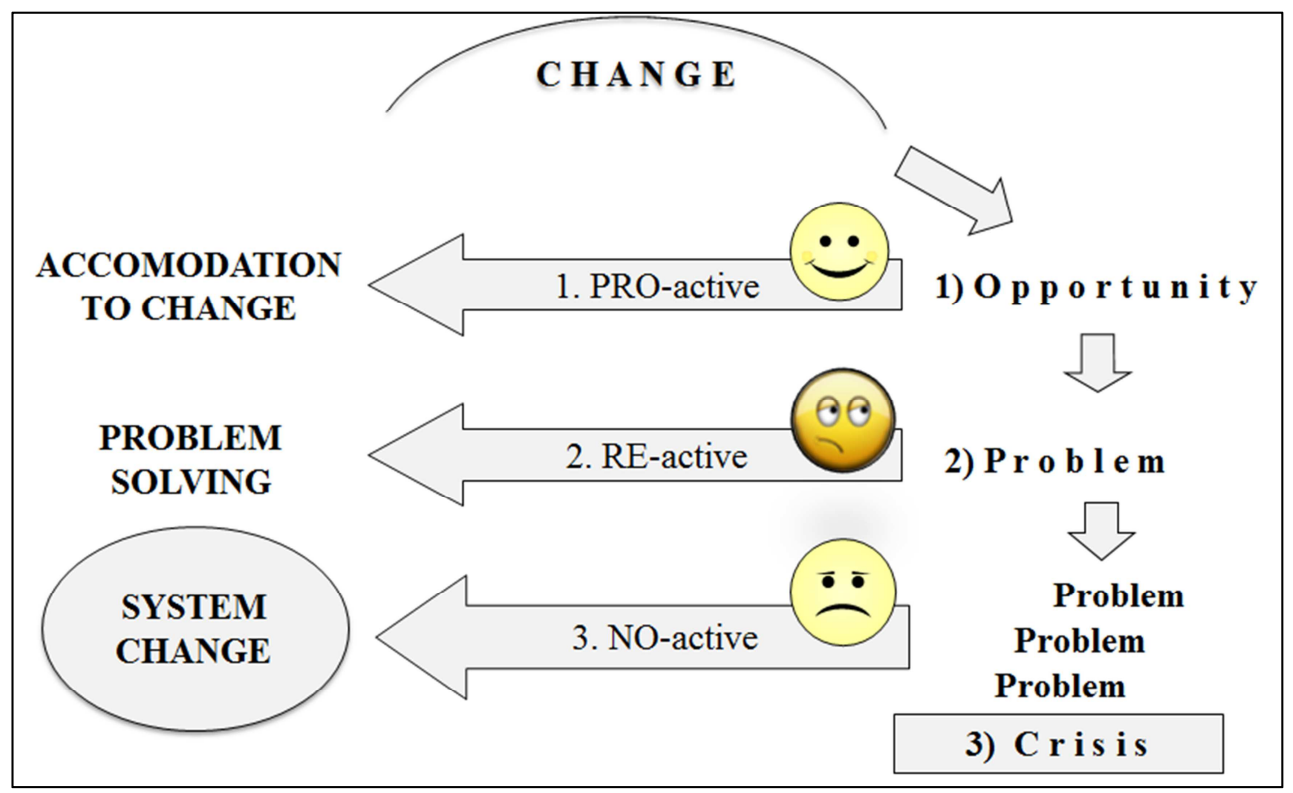

Diagram 4-Three different reactions on change

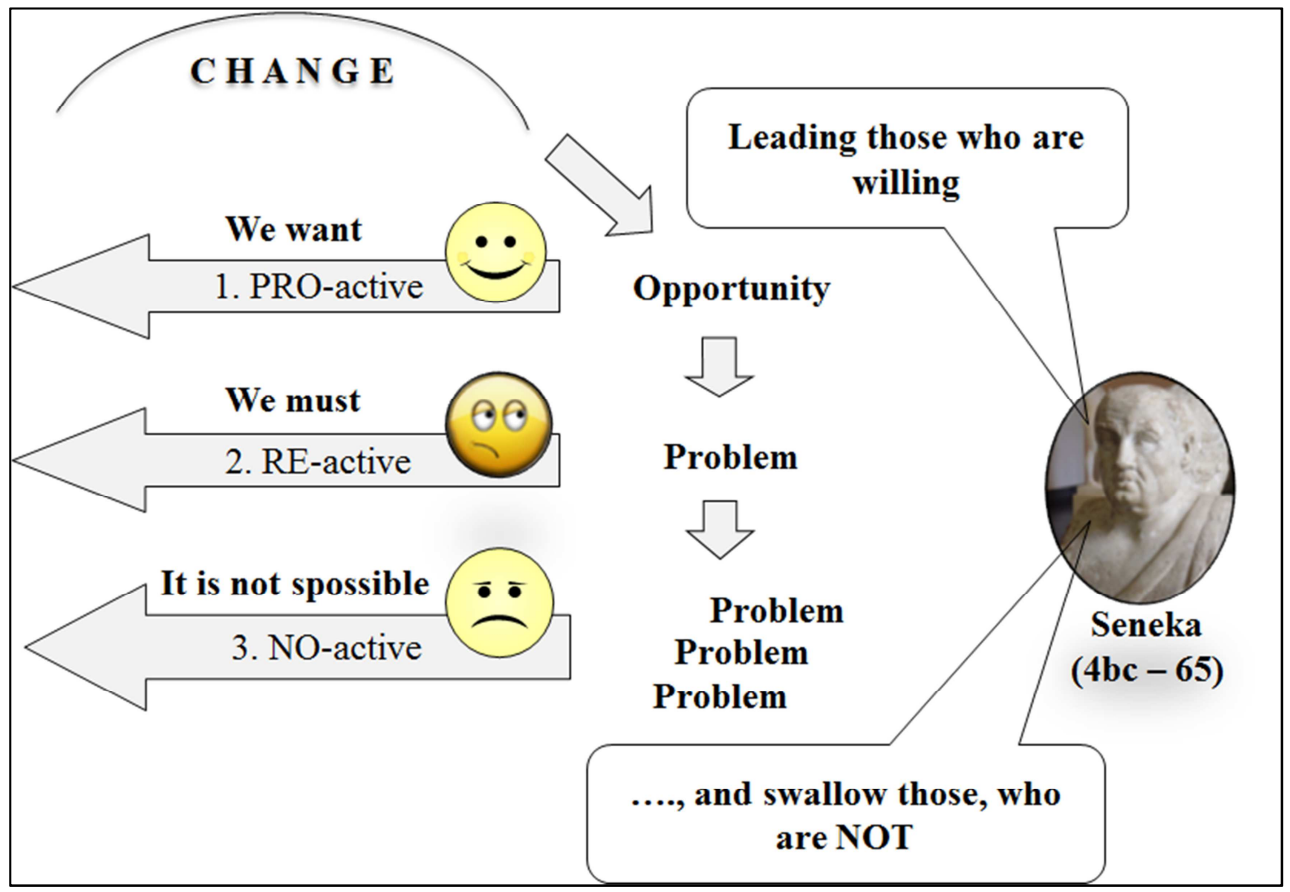

Diagram 5 - The role of culture, the role willingness (Kiauta, 2011) 


\subsubsection{Three different types of quality management styles in regards to changes}

If quality management is about planning, measuring, analyzing - learning and reacting-improving, than on three different fields of quality (must, competitive, attractive) we have three different sorts of activities, focusing on different goals.

- 1. Level quality management - To create higher level of safety, we are dealing with IMPROVEMENTS to reach demands.

- 2. Level quality management - To create higher level of value, we are dealing with IMPROVEMENTS to reach expectations.

- 3. Level quality management - To create higher level of sustainability, we are dealing with IMPROVEMENTS to react on new conditions and needs.

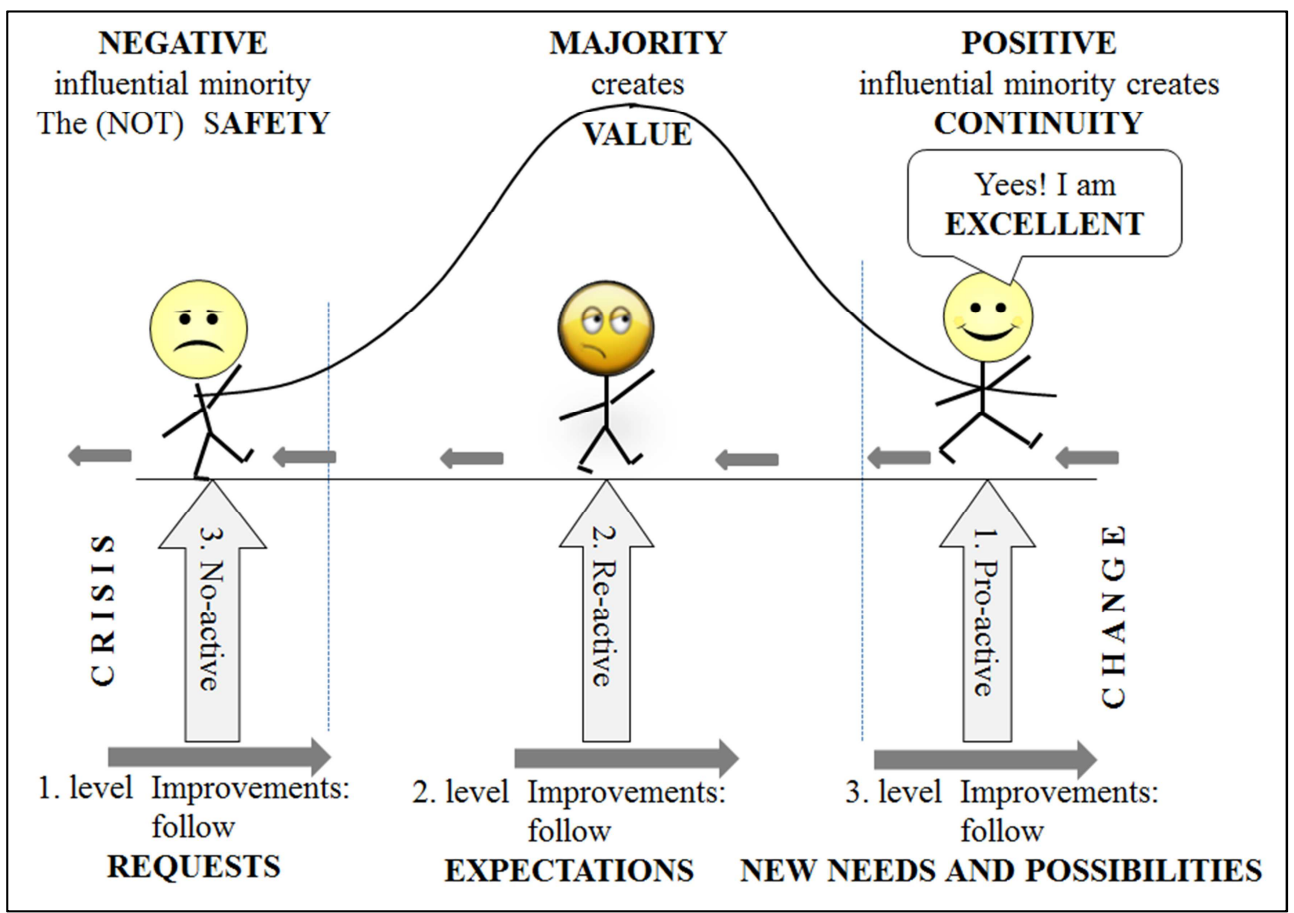

Diagram 6 - Three levels of improvements (Kiauta, 2011)

\subsubsection{Three different level of personal development}

The three styles of quality management should be connected with personal development. Each organization's employee's personal development is probably deployed according to gauss distribution. The bases of different approaches are different needs. Let us see the Trinity model of human needs (Dahlgaard-Park and Dahlgaard, 2003): 
- Physical or Biological Needs (living):

Food, Water, Air, Shelter, Clothing, Safety, Sex (biologically)

- Mental/Psychological Needs (learning):

Sense of belonging, Friends (mental love), Recognition, Individual identity, Achievement, Learning, Creativity, Development, Selffulfillment

- Spiritual Needs or Core Values (loving):

Searching and creating meaning, Trust, Justness, Honesty/openness, Loyalty, Integrity, Love (spiritual love), Sharing, Fairness, Respect

All three types of human needs are critical motivation factors. They should be considered simultaneously in each given situation. From an organizational perspective managers should work on improving the quality of employees' work life. For having un orientation on that subject, it is good hypothesis »Like space, also a person is expanding.« (Pavliha, 2010). I can try to explain, how I understand this idea:

- At first level of development he/she is focusing on him/her selves.

This enables us to be professionally good in our peace of work.

- On the second level he/she is focusing also on family and on customers of or in his organization. This enables us to be successful in serving to others.

- On the third level he/she is focusing on also on society and nature as a whole.

This enables us to understand what is going on, what is good and what is bad.

We need this level to be successful in corporate responsibility (ISO 26000:2010) and in risk management (ISO 31000:2009).

I assume, that these three levels can be in relations of three parts of human life, we can say $2 \times 30$ years. Humanity needs third part generations active (I am there ()). They are independent (?) and experienced. We should not measure our age with years, but with agility (easiness). Critical is building relations on the basis of hope and faith and not in fear.

\subsection{Relations between ISO 9001 and EFQM Model}

The standard would be less egocentric in regards to the QM specialists. For example: Instead of Measurement (paragraph 8.2) it would be better to be Results, and Customer results (paragraph 8.2.1), System results (paragraph 8.2.2), Processes results (paragraph 8.2.3) and product and system results (paragraph 8.2.4). If we integrate this in existing QMS there would be integrated also view of People results, Society results and Key (strategic) results. 
Activities of writing report on the basis of the Model is natural content of analyze (paragraph 8.4) and that report would be natural input for management revue (paragraph 5.6). And so on...

\section{Words are very important. We change world by changing words!}

\section{CONCLUSION}

We really need to amplify and to understand the concept of quality in a much wider way. To treat excellence related activities separated from all others quality management activities is not god solution. We live in time, when systems, organizations and society are falling apart. This is not healthy. We need integration moments. Integration is other word for creativity and health. It leads to integrity. Excellence is only one of three states of quality. If we ask: How? The answer is bad, good or excellent. All three are possible states of the same parameter.

There is no doubt: the idea of quality and excellence are not alternative. It is necessary to manage quality in all areas of activities both of individuals and of organizations. In this we follow development of an individual and of an organization on the road from results back to the causes.

- development lead an individual from acts to the awareness of words and thoughts, that caused that acts;

- development lead an organization from product/service to processes and from them to the environment in which those processes operate and finally from environment to leadership which created that environment.

The expanding concept of integrity led development efforts. Individuals and organizations differ both in field of quality management (higher or lower integrity), and in the level of quality that they reach in different fields.

High level on the field of results is needed for the current success. High level of quality in the fundamental causes (thought/leadership) is needed to ensure maximum sustainability.

And when »we care more, than others think is wise, risk more, than others think is safe, dream more, than others think is practical, and expect more, than others think is possible (Dahlgaard-Park, 2009), we are on the way towards excellence. 


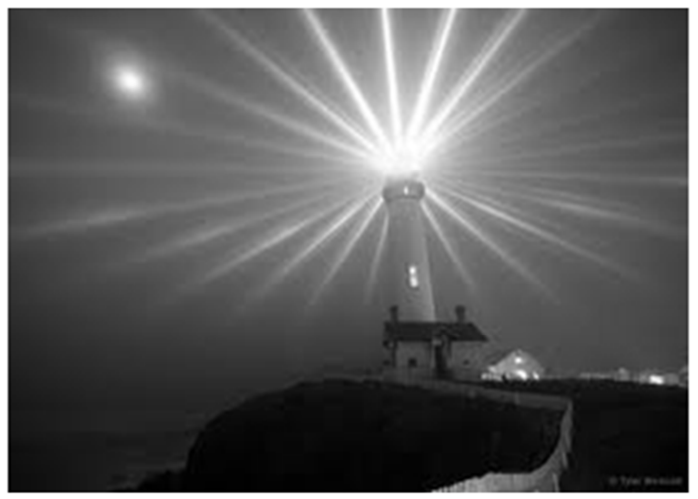

Let me finish with the poem of our Slovenian poet Srečko Kosovel:

"No paragraphs no laws just work will show to human race new way, and where the heart of genius foresaw only there mankind will go".

Figure 1 - Humanity needs examples of excellence as lighthouses for all others who would like to follow!

As regards quality, we must not follow bad examples of good idea being compromised by bad implementation (sociality-socialism, quality-certification, and excellence-reward). Humanity needs values as sociality, excellence and quality. They are not property of those, who earn money with their interpretation. We are not allowed to change their meaning for our current business interests.

\section{REFERENCES}

Adizes, I. C., (2009), How to Manage in Times of Crisis, Asee, Novi Sad.

Adizes, I. C., (2011), Category Archives: Managerial Insights [blog], Available at: http://www.ichakadizes.com/category/managerial-insights/

Cobb, C. G., (2003), From quality to business excellence: A systems approach to management, Wisconsin: ASQ Quality Press.

Dahlgaard-Park S. M. (2009), Decoding the Code of Excellence, International Journal of Quality and Service Sciences, Vol. 1 (1), pp. 5-28

Dahlgaard-Park S. M. and Dahlgaard J. J. (2003), "The Human Dimension: Critical to Sustainable Quality", In Conti, T., Kondo, Y. \& Watson, G. (eds.) Quality into the $21^{\text {st }}$ Century - Perspectivesvon Quality, Competitiveness \& Sustained Performance, Milwaukee, Wisconsin: ASQ Press, pp. 73-103.

International Organization for Standardization (2009), ISO 31000:2009 Risk management -- Principles and guidelines, Geneva: ISO.

International Organization for Standardization (2010), ISO 26000:2010 Guidance on social responsibility. Geneva: ISO. 
Wikipedia contributors (2012), "Kano model", Wikipedia, The Free Encyclopedia,

http://en.wikipedia.org/w/index.php?title=Kano_model\&oldid=525667424

Kiauta, M. (2011), Kako se odzivamo na krizo? (How we react to the crisis?), Bulletin: Economics, Organisation and Informatics in Healthcare, University of Primorska, Faculty of Mathematics, Natural Sciences and Information Technology, Versita, Koper

Kosovel, S., (1976), Red atom, Partizanska knjiga, Ljubljana

Pavliha, M. (2010), We are not born only for ourselves alone, Libris, Koper

Shahar, B. (2012), "Learn to fail or fail to learn", The happiness coach [blog], March 15, Available at: http://thehappinesscoach.biz/learn-to-fail-or-fail-to-learn

\section{ABOUT THE AUTHOR}

Marko Kiauta, University Dipl. Ing. of Electrical Engineering, Tangram TQC d.o.o. Consulting \& Engineering Ltd.; Slovenia, e-mail: tangramtqc@ amis.net 